\title{
A novel knowledge engineering application platform for armored vehicles
}

\author{
Jianjun Lin ${ }^{\mathrm{a}}$, Dong $\mathrm{Yu}{ }^{\mathrm{b}}$, Bo $\mathrm{Li}^{\mathrm{c}}$ \\ China North Vehicle Research Institute, Beijing 100072, China. \\ a11267216@qq.com, b dysunshine@126.com, 'boli2@noveri.com.cn
}

\begin{abstract}
Keywords: Armored vehicles, knowledge innovation platform, knowledge system framework, process management.
\end{abstract}

\begin{abstract}
As a practical application of knowledge innovation mode, knowledge innovation platform can improve enterprise dynamic capabilities and sustainable competitive advantages which have great significance. Knowledge innovation platform can be applied to the production systems of actual models or engineering so that we have a sound knowledge base and reusable libraries for designing process management and control, customization and application of template gallery, in order to solve problems in engineering application. In the engineering background of armored vehicle production system, we put forward the integration framework based on knowledge innovation platform, analyzed the demand of the production system, designed innovation platform system architecture, and clarified the key technology of system. Practical results showed that this innovation platform system played an important and significant role in reducing cost and improving the efficiency of knowledge innovation.
\end{abstract}

\section{Introduction}

In the era of knowledge economy and business cooperation, we build knowledge innovation platform based on the dynamic capability, which can realize the effective management of knowledge and resource sharing and complementary in the collaborative chain, improve the efficiency of innovation and better adapt to the environment changes, so as to effectively improve enterprise dynamic response ability and the core competitive advantages. Collaborative management is based on the spirit of cooperation concept, using Internet technology, to integrated optimize the enterprise internal and external resources and business process, and realize the full development and utilization of resources. Its essence is to break the various barriers and boundaries between the resources (people, money, material, information and process, etc.), making them coordinated operate for a common goal. Through the development, utilization and appreciation of various resources efficiently, collaborative management fully realize the goal of collaborative enterprise mutual benefit and a win-win aspect [1]. With the advent of the knowledge economy era, knowledge resources becomes the most important resource, and knowledge innovation has become the soul of enterprise core competitiveness and sustainable development ability.

At present, the knowledge management research field received wide attention of experts and scholars both at home and abroad. C.M. Li.et al [2] discussed the knowledge sharing characteristics, influencing factors and main problems of collaborative knowledge innovation. They combined collaborative knowledge management theory with knowledge governance theory to analysis and discuss the process of knowledge sharing and management mechanism. They build knowledge sharing system for enterprise cooperative knowledge innovation. Richard.et al [3] proposed a knowledge management technology, which core part is the risk analysis, the update of the process of knowledge management and strategic analysis of knowledge ability. The technology can be used to eliminate the islands of knowledge in business enterprise, and promote knowledge sharing and knowledge innovation within the enterprise. Morten.et al [4] analyzed STI and DUI which are two kinds of different patterns of innovation, namely STI mode based on coding of the dominance of science and technology and the implicit DUI mode based on the learning experience. They 
demonstrated that combine the two innovation modes will be more effectively realize knowledge innovation than just rely on one. Z.B. Wang [5] discussed close link between the system platforms, and considered the decision-making of platform, knowledge innovation, achievements transformation and diffusion, and monitoring and evaluation as the industry technology innovation platform integrated synergies between different systems which are cooperated. However, the research for actual application of knowledge engineering innovation platform is less.

This paper proposed a knowledge innovation design platform of engineering application used in armored vehicles production system management. Firstly, we designed platform system architecture by analyzing framework needs; Then we described the key technologies in the subsystems, and verified the application effect of knowledge engineering application platform; in the finally, we summarized.

\section{Innovative design platform system architecture}

Innovative design platform system was supposed to fully realize project schedule management, task tracking and control, resource allocation and optimization, mainly including data management, process management, rights management, report generation, knowledge management, the reusable parts database, design knowledge; we need establish knowledge representation mechanism, and put the optimal design method and process of implicit knowledge into normal display; we must collaborative use product development engineering and project management process information, in order to provide effective tools support for the coordinated development and management.

This paper adopted B/S mode to develop the platform. The model unified the client, and focused the core of the system function realization part on the server (database server, file server, calculate server), simplifying the development, maintenance and use of the system. In addition, we used Ajax technology to design page, making the system function on the client computer part processing, thus greatly reduced the burden of the server; and increased the interactivity, local real-time refresh, improved the user experience of application. System architecture is showed in Fig.1.

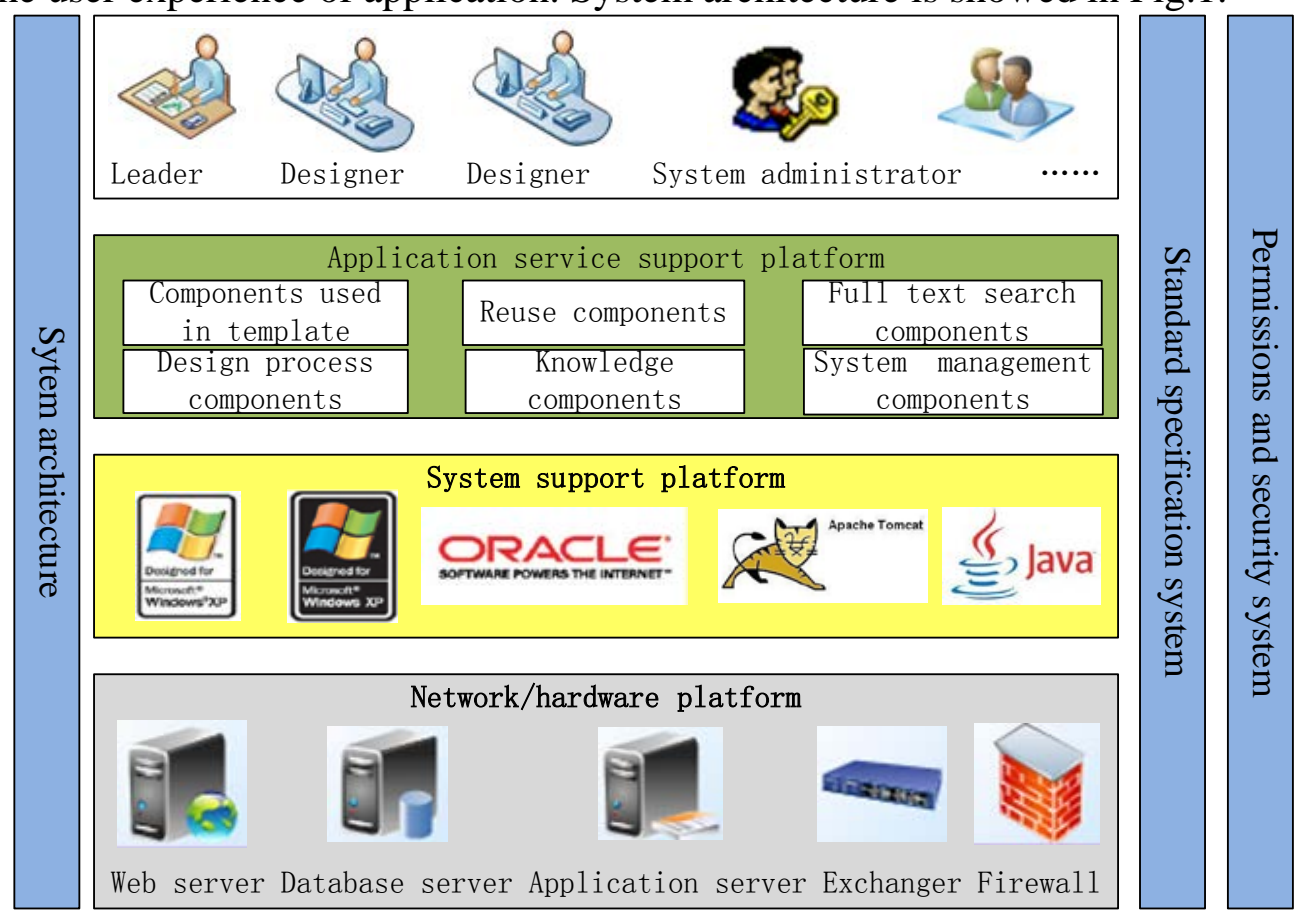

Fig.1 System architecture of the innovative design platform

Based on B/S mode architecture, the system made up of three basic layer structure (the presentation layer, business logic layer and data service layer) was extended to five layer structure (the presentation layer, business layer, platform layer, data model layer, data service layer). The system hierarchy is showed in Fig.2. 


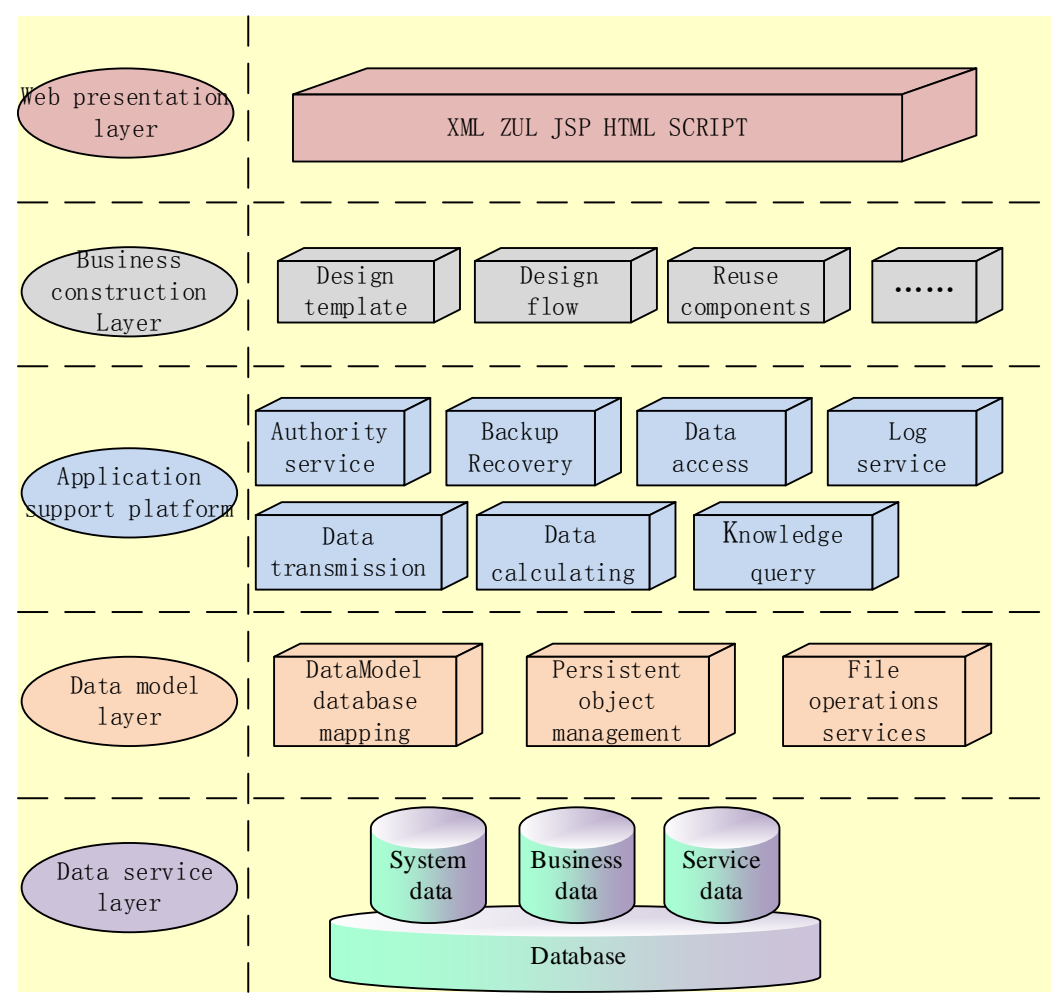

Fig.2 General Structure of the system

Above the picture, Web presentation layer is the operation interface of system all functions, which is responsible for data input and results display output. Business building layer shows the whole system function modules. Application support platform provides all the support system function modules, including the system login, access control, data and file access, log management, data calculation, etc.

\section{The key technology of subsystem and application verification}

This innovative application platform core subsystems include: reuse components subsystem, design process subsystem, design templates subsystem. The execution process of the application platform and relationship between subsystems as shown in Fig.3.

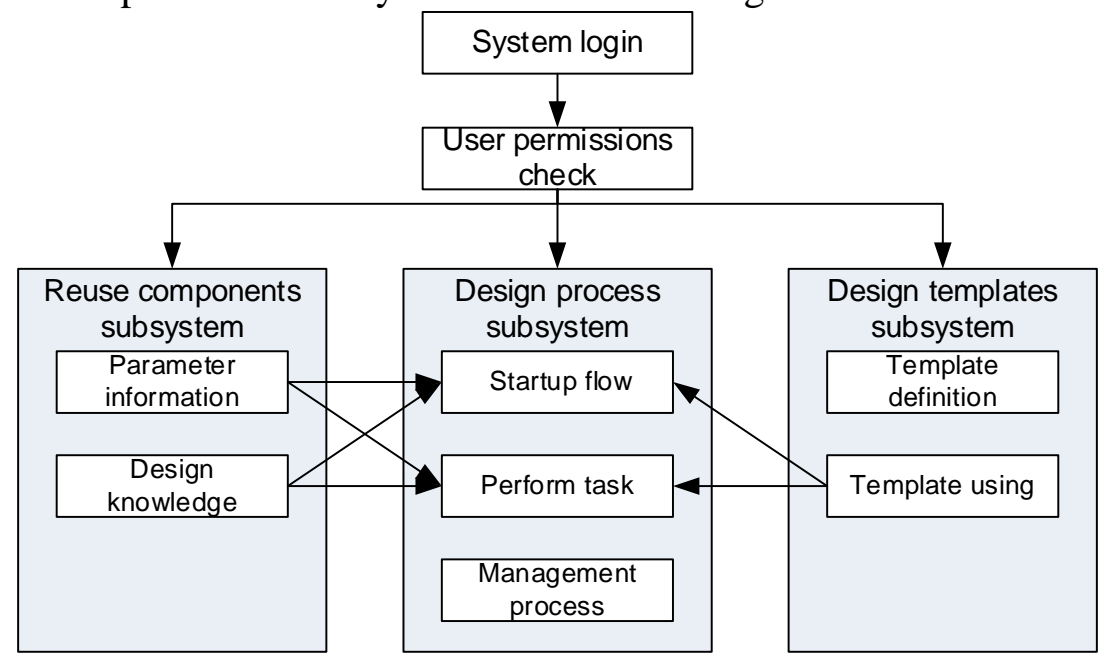

Fig. 3 The execution process of the application platform and relationship between subsystems

The key technology of reuse components subsystem is classifying management for existing models, components, models of the parts, documents, properties of the parts, and so on. The key technology of design process subsystem is provide flexible and can be customized design process, and the design process of standardization for standard XML format documents, using process scheduling engine manage and control the design process. The key technology of design templates 
subsystem is via a browser input parameters, and automatic call server or client computing template, to simply and standardize design and analysis of the product.

By popularization and use in armored vehicle production system, the platform realized structured management of the stereotyped models, components, part models and the properties of part, providing the reference to the designers in the selection of the new model and deformation design, analysis, and so on. We put mature design and analysis process into a template, and realized the automation of the design for the repetitive tasks. The application effect of knowledge engineering application platform as shown in Fig.4.

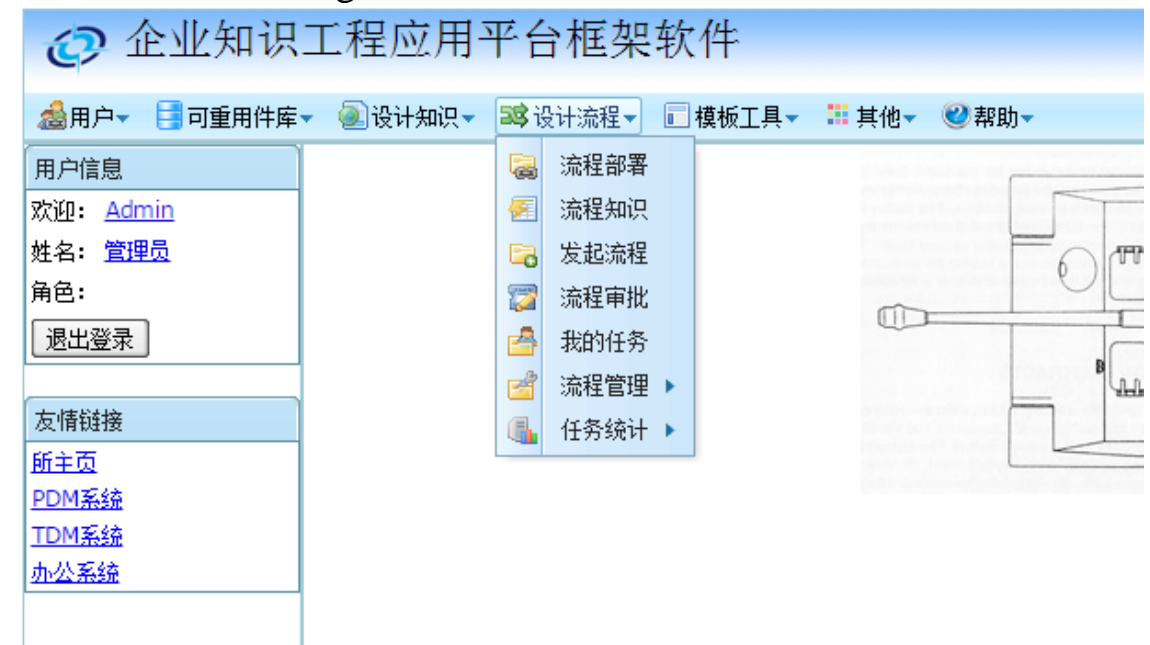

Fig.4 The application effect of knowledge engineering application platform

\section{Summary}

In the engineering background of armored vehicle production system, we put forward a knowledge innovation platform for engineering application. By analyzing the demand of the production system, we designed platform system architecture, expounded the key technologies of subsystems, and applied the innovation platform to armored vehicle production system. The experimental results showed that this innovation platform system can effectively reduce the cost and significantly improve the efficiency of knowledge innovation.

\section{Acknowledgment}

This work is supposed by National Natural Science Foundation of China (Grant No.61304206).

\section{References}

[1]. Chaoming Li, Xiasheng Chen. Study on the Model of Enterprises Coordinative Knowledge Innovation. Journal of Wuhan University of Technology (Information \& Management Engineering). Vol. 31 (2009) No. 1, p. 109-112.

[2]. Chaoming Li, Jingpo Liu. Knowledge Sharing of the Enterprises Collaborative Knowledge Innovation. Forum on Science and Technology in China. Vol. 6 (2012), p. 96-101+154.

[3]. R. Hall, P. Andriani. Managing Knowledge for Innovation. Long Range Planning. Vol. 35 (2002), p. 29-48.

[4]. M. B. Jensen, B. Johnson, E. Lorenz, B. Å. Lundvall. Forms of knowledge and modes of innovation. Research Policy. Vol. 36 (2007), p. 680-693.

[5]. Zhibo Wang. Research on the System Model Framework and Elements of Industry Technology Innovative Platform. Science and Technology Management Research. (2012) No. 11, p. 17-20 